\title{
Total Blood Mercury Predicts Methylmercury Exposure in Fish and Shellfish Consumers
}

\author{
Ellen M. Wells ${ }^{1,2} \cdot$ Leonid Kopylev $^{3} \cdot$ Rebecca Nachman $^{3} \cdot$ Elizabeth G. Radke $^{3} \cdot$ Johanna Congleton $^{3}$. \\ Deborah Segal ${ }^{3}$ (I)
}

Received: 24 August 2021 / Accepted: 12 October 2021 / Published online: 23 October 2021

This is a U.S. government work and not under copyright protection in the U.S.; foreign copyright protection may apply 2021

\begin{abstract}
Many studies evaluating methylmercury $(\mathrm{MeHg})$ toxicity rely on whole blood total mercury $(\mathrm{THg})$ measurements to estimate MeHg exposure. However, whole blood THg includes other forms of mercury ( $\mathrm{Hg}$ ), such as inorganic $\mathrm{Hg}$, which have different exposure sources and toxicological effects than $\mathrm{MeHg}$. Therefore, estimating the whole blood $\mathrm{MeHg} / \mathrm{THg}$ ratio is critical to predicting $\mathrm{MeHg}$ exposure and, subsequently, efforts to establish an exposure-response relationship for use in risk assessment. A large, representative dataset (National Health and Nutrition Examination Survey (NHANES) 2011-2016) was used to determine the whole blood $\mathrm{MeHg} / \mathrm{THg}$ ratio among (a) self-reported fish and shellfish consumers, $\geq 15$ years of age (the "full adult" population $(N=5268$ training dataset; $N=2336$ test dataset)) and (b) female fish and shellfish consumers, 15-44 years of age (the "women of reproductive age" population ( $N=1285$ training dataset; $N=560$ test dataset)). Unadjusted and adjusted linear and spline models with direct measurements for both $\mathrm{THg}$ and $\mathrm{MeHg}$ were evaluated. The mean whole blood $\mathrm{MeHg} / \mathrm{THg}$ ratio was 0.75 (95\% confidence interval (CI): 0.74, 0.75). This ratio was significantly higher among those with higher THg concentrations. All models exhibited excellent fit (adjusted $R^{2}$ from 0.957 to 0.982 ). Performance was slightly improved in spline versus linear models. For the full adult population and women of reproductive age, the unadjusted spline model predicted whole blood $\mathrm{MeHg}$ concentrations of $5.65 \mu \mathrm{g} / \mathrm{L}$ and $5.55 \mu \mathrm{g} / \mathrm{L}$, respectively, when the THg concentration was $5.80 \mu \mathrm{g} / \mathrm{L}$. These results suggest that whole blood $\mathrm{THg}$ is a good predictor of whole blood $\mathrm{MeHg}$ among fish and shellfish consumers.
\end{abstract}

Keywords Mercury $\cdot$ Methylmercury $\cdot$ Reproductive age $\cdot$ NHANES $\cdot$ Biomarkers $\cdot$ Seafood

$\begin{array}{llll}\text { Abbreviations } & & \text { IQR } & \text { Interquartile range } \\ \text { AIC } & \text { Akaike's Information Criterion } & \text { LOD } & \text { Limit of detection } \\ \text { BIC } & \text { Bayesian Information Criterion } & \text { LVR2 } & \text { Leverage versus squared residual } \\ \text { BMI } & \text { Body mass index } & \text { MeHg } & \text { Methylmercury } \\ \text { ICP-DRS-MS } & \text { Inductively coupled plasma dynamic reac- } & \text { MSE } & \text { Mean squared error } \\ & \text { tion cell mass spectrometry } & \text { NCHS } & \text { National Center for Health Statistics } \\ \text { IC-PMS } & \text { Inductively coupled plasma mass } & \text { NHANES } & \begin{array}{l}\text { National Health and Nutrition Examina- } \\ \text { tion Survey }\end{array}\end{array}$

Deborah Segal

Segal.Deborah@epa.gov

Ellen M. Wells

wells54@purdue.edu

Leonid Kopylev

kopylev.leonid@epa.gov

Rebecca Nachman

nachman.rebecca@epa.gov

Elizabeth G. Radke

radke-farabaugh.elizabeth@epa.gov
Johanna Congleton

congleton.johanna@epa.gov

1 School of Health Sciences, Purdue University, West Lafayette, IN, USA

2 Department of Public Health, Purdue University, West Lafayette, IN, USA

3 Center for Public Health and Environmental Assessment, Office of Research and Development, US Environmental Protection Agency, 1200 Pennsylvania Ave, Washington DC, NW 20460, USA 


$\begin{array}{ll}\text { RVF } & \text { Residual versus fitted } \\ \text { THg } & \text { Total mercury } \\ \text { TSID } & \text { Triple spike isotope dilution } \\ \text { US CDC } & \begin{array}{l}\text { United States Centers for Disease Control } \\ \text { and Prevention }\end{array} \\ & \text { United States Environmental Protection } \\ \text { US EPA } & \text { Agency } \\ & \text { United States } \\ \text { USA } & \text { World Health Organization }\end{array}$

\section{Introduction}

Mercury $(\mathrm{Hg})$ is a naturally occurring heavy metal of great concern to public health. Ample research has demonstrated that exposure to various forms of $\mathrm{Hg}$ is associated with impaired neurodevelopment [1-3], nervous system effects in adults [4-6], cardiovascular diseases [7, 8], and renal toxicity $[9,10]$. Globally, the World Health Organization (WHO) has designated $\mathrm{Hg}$ as one of the ten most dangerous chemicals to public health [11].

The chemical form of $\mathrm{Hg}$ affects its environmental fate and transport, sources of exposure, and toxicity. Health concerns have been associated with exposure to elemental $\mathrm{Hg}$ (Hg vapor) [5, 12], inorganic $\mathrm{Hg}[10,13]$, and methylmercury $(\mathrm{MeHg})[14,15]$. However, exposure to $\mathrm{MeHg}$ is a particular public health concern due to its well-documented neurotoxicity, particularly among children [14, 15]. Additionally, $\mathrm{MeHg}$ is the most common form of $\mathrm{Hg}$ to which humans are exposed [16], and a substantial proportion of the US population is likely exposed to $\mathrm{MeHg}$ at concentrations above recommended limits [17].

Consequently, regulatory agencies have developed guidelines specific to $\mathrm{MeHg}$, including a reference dose by the US Environmental Protection Agency (US EPA) [18, 19]. The current reference dose, which is based on neurodevelopmental effects resulting from in utero exposure, is equivalent to a cord blood $\mathrm{MeHg}$ concentration of $5.80 \mu \mathrm{g} / \mathrm{dL}$ [19]. As it has been estimated that cord whole blood $\mathrm{MeHg}$ is 1.7 times higher than maternal whole blood [20], this would be equivalent to a maternal whole ${ }^{1}$ blood $\mathrm{MeHg}$ concentration of $3.40 \mu \mathrm{g} / \mathrm{dL}$. However, the technology to measure $\mathrm{MeHg}$ and other specific forms of $\mathrm{Hg}$ directly has not been widely available and is expensive. Because $\mathrm{MeHg}$ was demonstrated to comprise approximately $90 \%$ of blood total mercury (THg) [16], the use of blood THg concentrations as a proxy for blood $\mathrm{MeHg}$ has been recommended [16, 21]. As a result, many research studies that evaluate the toxicity of $\mathrm{MeHg}$ have utilized measurements of blood $\mathrm{THg}$, which

${ }^{1}$ In the rest of the article, whole blood will be referred to as blood. includes $\mathrm{MeHg}$ as well as all forms of mercury, to estimate $\mathrm{MeHg}$ exposure.

More recent studies have suggested that the percentage of blood $\mathrm{THg}$ comprising $\mathrm{MeHg}$ may be highly variable as well as lower than previously estimated [22], with some results only reaching $61-63 \%$ [23]. This has led to concern that measuring $\mathrm{THg}$, instead of $\mathrm{MeHg}$, may result in exposure misclassification in which $\mathrm{MeHg}$ exposure is overestimated, leading to inexact estimations of its health effects $[24,25]$. Thus, this poses a challenge for risk assessors, as it is unclear how to use the numerous studies that rely on measurements of blood THg in an exposure-response analysis for MeHg. Therefore, a model was developed to determine the relationship between $\mathrm{THg}$ and $\mathrm{MeHg}$ in blood. This was accomplished using data from the National Health and Nutrition Examination Survey (NHANES), which includes a large nationally representative population and direct measurements of both blood $\mathrm{THg}$ and $\mathrm{MeHg}$. Although others have measured both $\mathrm{THg}$ and $\mathrm{MeHg}$ in blood, to the best of our knowledge, this manuscript presents the first model developed to predict blood $\mathrm{MeHg}$ based on blood $\mathrm{THg}$ measurements.

\section{Methods}

We used data from NHANES, a cross-sectional survey conducted by the US Centers for Disease Control (CDC) of the non-institutionalized civilian US population in the 50 states and the District of Columbia. NHANES consists of a questionnaire and physical exam, during which blood samples are collected. At the time of analysis, directly measured $\mathrm{THg}$ and $\mathrm{MeHg}$ concentrations were available for NHANES data collected from 2011 to 2016 . These were randomly divided into two datasets: one was used to create the prediction model, i.e., the "training" dataset, and the other was used to test the model, i.e., the "test" dataset. NHANES participants sign informed consent documentation prior to participation; NHANES operates under an approved protocol from the National Center for Health Statistics (NCHS) Ethics Review Board. More details about NHANES are available online at https://www.cdc.gov/nchs/nhanes/index.htm.

A study participant flowchart is presented in Supplemental Figure $\mathrm{S} 1$. There were $N=29,902$ participants in NHANES 2011-2016. $N=11,953$ participants were excluded because they did not have THg and/or MeHg blood measurements. Of note is that, in 2011-2012, NHANES measured $\mathrm{THg}$ and $\mathrm{MeHg}$ for the entire population providing a blood sample, but starting in 2013, only a random 50\% sample of the full population who provided blood had their samples analyzed for $\mathrm{Hg}$. Participants with missing data on other model covariates (income, $N=1409$; body mass index (BMI), $N=586$; self-reported fish consumption, $N=178$ ) 
were also excluded. As this analysis is heavily reliant on laboratory measurements of blood $\mathrm{Hg}$, we excluded groups with a high rate of blood $\mathrm{Hg}$ concentrations below the detection limit: younger participants $(<15$ years old; $33.5 \%$ of $\mathrm{THg}$ was $<$ LOD) and non-fish or shellfish consumers (31.9\% of $\mathrm{THg}$ was $<\mathrm{LOD}$ ). $N=5323$ participants were excluded because they were less than 15 years old, and $N=2,867$ participants were excluded because they did not report eating fish or shellfish within the past 30 days. This left a total of $N=7604$ for analyses, referred to as the "full adult" population. In addition, as much of the existing epidemiologic studies on $\mathrm{Hg}$ focuses on prenatal exposures, we were specifically interested in women of reproductive age. Thus, we also created models within the subset of female fish and shellfish consumers who were of reproductive age (15 to 44 years, $N=1845$ ), referred to as the "women of reproductive age" population. Two-thirds of this population was randomly selected to be in the training dataset $(N=5268$ full adult, $N=1285$ women of reproductive age) and the remainder were included in the test dataset $(N=2336$ full adult, $N=560$ women of reproductive age).

Blood samples were collected by trained phlebotomists using metal-free containers. Samples were frozen $\left(-30^{\circ} \mathrm{C}\right)$ until shipment to the US CDC. They were transferred to the US CDC Division of Laboratory Sciences (Atlanta, Georgia) within the National Center for Environmental Health for $\mathrm{Hg}$ determination. All quality assurance and quality control protocols for $\mathrm{Hg}$ assessment meet the 1988 Clinical Laboratory Improvement Act mandates [26, 27]. Other than the change in the limit of detection for $\mathrm{THg}$ (described below), the laboratory procedures did not change over time.

Blood $\mathrm{THg}$ was determined using quadrupole inductively coupled plasma mass spectrometry (ICP-MS) (ELAN DRC II; PerkinElmer, Norwalk, CT, USA). This method detects the mass-to-charge ratio for each ion in the sample, which is used to determine the element and its concentration. The limit of detection (LOD) for blood $\mathrm{THg}$ was $0.16 \mu \mathrm{g} / \mathrm{L}$ in 2011-2012 and 0.28 in 2013-2016. To ensure that this did not cause any bias in our analysis, a uniform LOD $(0.28)$ was applied to all THg samples; this affected 163/5268 measurements, or $3.1 \%$ of the full population training dataset. Values $<$ LOD were replaced with $\mathrm{LOD} / \sqrt{ }(2)$ for analyses. In the training dataset, there were $407 / 5268$ (7.7\%) values $<$ LOD (full adult) and 121/1825 (9.4\%) values $<$ LOD (women of reproductive age). Corresponding values for the test dataset were 172/2336 (7.4\%) (full adult) and 58/560 (10.4\%) (women of reproductive age).

$\mathrm{MeHg}$ concentration was determined using a triple spike isotope dilution (TSID) method; gas chromatography (GC) (Clarus 500; PerkinElmer, Norwalk, CT, USA) was used to separate $\mathrm{Hg}$ forms. This was followed by inductively coupled plasma dynamic reaction cell mass spectrometry (ICP-DRC-MS) (NexION 300D; PerkinElmer, Norwalk,
CT, USA) for quantification. Hg forms in blood were measured using stannous chloride as a reductant. This method has a MeHg LOD of $0.12 \mu \mathrm{g} / \mathrm{L}$; this did not change over the time period included in this analysis. Similar to $\mathrm{THg}$, values $<\mathrm{LOD}$ were replaced with $\mathrm{LOD} / \sqrt{ }(2)$. In the training dataset, there were 351/5268 (6.7\%) values $<\mathrm{LOD}$ for $\mathrm{MeHg}$ (full adult) and 104/1285 (8.1\%) values < LOD (women of reproductive age). Corresponding values for the test dataset were 129/2336 (5.5\%) (full adult) and 37/560 (6.6\%) (women of reproductive age).

Demographic data (age, sex, fish and shellfish consumption, race/ethnicity, income) were obtained via questionnaire. Categories used for race/ethnicity were non-Hispanic white, non-Hispanic black, Hispanic (indicated as "Mexican-American" or "Other Hispanic"), Asian, and mixed race/other. Income was defined as annual household income. Weight and height were collected at the physical examination. BMI was calculated as weight $(\mathrm{kg}) /(\text { height }(\mathrm{m}))^{2}$ and classified as normal or underweight $(\mathrm{BMI}<25)$, overweight (BMI 25 to 29.9), and obese (BMI $\geq 30$ ).

Stata 13.0 (College Station, TX, USA) was used for statistical analyses; a $p$ value of 0.05 was considered to be statistically significant, using Pearson or Wald Chi-square tests as appropriate. The training dataset was used to create a model which would predict MeHg concentrations. NHANES is designed to obtain a representative sample of the USA; the use of appropriate survey weights and analytic methods is needed to obtain statistical results that reflect this representative sampling. However, as the goal for this analysis is not to describe the prevalence of $\mathrm{MeHg}$ within the US population and not all model development statistics are readily applied to survey data, survey weights and analytic methods were not used in this analysis. This could affect the variance of some variables; it also means that the population included in the analysis does not reflect a representative sample of the USA.

We explored the relationship between $\mathrm{MeHg}$ and $\mathrm{THg}$ blood concentrations. Both were approximately lognormally distributed; thus, central tendencies are reported using geometric means and log scales are used in some figures. Several unadjusted models with blood $\mathrm{THg}$ as the independent variable and blood $\mathrm{MeHg}$ as the dependent variable were created to explore model fit, including linear, linear with natural-log transformations for $\mathrm{MeHg}$ and/or $\mathrm{THg}$, spline, and cubic spline models. We evaluated model fit using model $R^{2}$, mean squared error (MSE), Akaike's Information Criterion (AIC), Bayesian Information Criterion (BIC), residuals, leverage, residual versus fitted (RVF) plots, and leverage versus squared residual (LVR2) plots. Model covariates were selected based on preliminary evaluation of their associations with blood $\mathrm{MeHg}$ and $\mathrm{THg}$; additionally, these are commonly used covariates which have been reported to be associated with $\mathrm{MeHg}$ and $\mathrm{THg}$ in other 
Table 1 Population characteristics among fish and shellfish consumers, NHANES 2011-2016

\begin{tabular}{|c|c|c|c|c|c|c|}
\hline & \multicolumn{3}{|c|}{ Full adult population } & \multicolumn{3}{|c|}{ Women of reproductive age } \\
\hline & Training dataset & Test dataset & $p$ & Training dataset & Test dataset & $p$ \\
\hline$N$ & 5268 & 2336 & & 1285 & 560 & \\
\hline \multicolumn{7}{|l|}{ Age } \\
\hline $15-29$ & $1272(24.2)$ & $568(24.3)$ & & $644(50.1)$ & $283(50.5)$ & \\
\hline $30-44$ & $1241(23.6)$ & $534(22.9)$ & & $641(49.9)$ & $277(49.5)$ & 0.869 \\
\hline $45-59$ & $1220(23.2)$ & $535(22.9)$ & & - & - & \\
\hline $60+$ & $1535(29.1)$ & 699 (29.9) & 0.863 & - & - & \\
\hline \multicolumn{7}{|l|}{ Sex } \\
\hline Female & $2704(51.3)$ & $1177(50.4)$ & & - & - & \\
\hline Male & $2564(48.7)$ & 1159 (49.6) & 0.448 & - & - & \\
\hline \multicolumn{7}{|l|}{ Race/ethnicity } \\
\hline NH white & $1965(37.3)$ & $922(39.5)$ & & $377(29.3)$ & $176(31.4)$ & \\
\hline NH black & $1300(24.7)$ & $537(23.0)$ & & $337(26.2)$ & $132(23.6)$ & \\
\hline Hispanic & $1176(22.3)$ & $538(23.0)$ & & $341(26.5)$ & $152(27.1)$ & \\
\hline NH Asian & $637(12.1)$ & 273 (11.7) & & $176(13.7)$ & $82(14.6)$ & \\
\hline Multiracial/other & $190(3.6)$ & $66(2.8)$ & 0.115 & $54(4.2)$ & $18(3.2)$ & 0.570 \\
\hline \multicolumn{7}{|l|}{ Household income } \\
\hline$<\$ 20,000$ & $1060(20.1)$ & $518(22.2)$ & & $229(17.8)$ & $132(23.6)$ & \\
\hline$\$ 20,000$ to $\$ 44,999$ & $1587(30.1)$ & $678(29.0)$ & & $397(30.9)$ & $163(29.1)$ & \\
\hline$\$ 45,000$ to $\$ 74,999$ & $1029(19.5)$ & $441(18.9)$ & & $268(20.9)$ & $105(18.8)$ & \\
\hline$\geq \$ 75,000$ & $1592(30.2)$ & $699(29.9)$ & 0.226 & $391(30.4)$ & $160(28.6)$ & 0.040 \\
\hline \multicolumn{7}{|l|}{ Body mass index } \\
\hline$<25 \mathrm{~kg} / \mathrm{m}^{2}$ & $1732(32.9)$ & $747(32.0)$ & & $537(41.8)$ & $226(40.4)$ & \\
\hline 25 to $29.9 \mathrm{~kg} / \mathrm{m}^{2}$ & $1619(30.7)$ & 739 (31.6) & & $299(23.3)$ & $137(24.5)$ & \\
\hline$\geq 30 \mathrm{~kg} / \mathrm{m}^{2}$ & $1917(36.4)$ & $850(36.4)$ & 0.661 & 449 (34.9) & $197(35.2)$ & 0.804 \\
\hline \multicolumn{7}{|c|}{ No. of seafood meals/30 days } \\
\hline 1 to 2 meals & $1736(33.0)$ & $760(32.5)$ & & $472(36.7)$ & $198(35.4)$ & \\
\hline 3 meals & 605 (11.5) & $309(13.2)$ & & $161(12.5)$ & $80(14.3)$ & \\
\hline 4 to 7 meals & $1527(29.0)$ & $670(28.7)$ & & $325(25.3)$ & 149 (26.6) & \\
\hline$\geq 8$ meals & $1400(26.6)$ & $597(25.6)$ & 0.182 & $327(25.5)$ & $133(23.8)$ & 0.607 \\
\hline
\end{tabular}

Full: $\geq 15$ years old; Reproductive: women 15 to 44 years old. NHANES, National Health and Nutrition Examination Survey; $N H$, non-Hispanic. Values are percent (95\% confidence interval). Pearson's chisquare test is used to compare training versus test datasets; bold type indicates $p<0.05$ studies. Specifically, associations of the $\mathrm{MeHg} / \mathrm{THg}$ ratio have been reported with age [28, 29], sex [22], race/ethnicity [28], and fish and shellfish consumption [29]. Model covariates included age (continuous), sex (binary), race/ethnicity (categorical), income (categorical), and BMI (categorical). Model fit statistics described above were used to evaluate model fit. These models were also used to predict blood $\mathrm{MeHg}$ concentrations using the test dataset.

\section{Results}

Unadjusted models were created for linear, linear with natural-log transformations for $\mathrm{MeHg}$ and/or $\mathrm{THg}$, spline, and cubic spline models. The natural-log transformed models had the poorest fit and were therefore not considered in detailed analyses (data not shown). The spline models, including the cubic spline, were roughly similar, so the best fitting spline model, with a knot at $1 \mu \mathrm{g} / \mathrm{L} \mathrm{THg}$, was used in further analyses along with the linear model.

Demographic characteristics are shown in Table 1. Across both the training and test datasets, the mean age is $46.3(95 \%$ confidence interval (CI): 45.9, 46.7) (full adult) and 29.3 (95\% CI: 28.9, 29.7) (women of reproductive age). A majority of participants are non-Hispanic white, have household incomes greater than $\$ 45,000$, and are classified as overweight or obese. Women of reproductive age in the training dataset had a statistically significant higher income than women in the test datasets; however, this did not appear to substantially influence results.

Average blood $\mathrm{Hg}$ concentrations and the $\mathrm{MeHg} / \mathrm{THg}$ ratio are presented in Table 2 . Across both the training and 
Table 2 Whole blood mercury concentrations, fish and shellfish consumers, NHANES 2011-2016

\begin{tabular}{lllllllll}
\hline & \multicolumn{2}{l}{ Full adult population } & & & Women of reproductive age & \\
\cline { 2 - 3 } & Training dataset & Test dataset & $p$ & & Training dataset & Test dataset & $p$ \\
\hline$N$, all & 5268 & 2336 & & 1285 & 560 & \\
$\mathrm{THg}, \mu \mathrm{g} / \mathrm{L}$ & $0.99(0.97,1.02)$ & $0.99(0.95,1.03)$ & 0.975 & & $0.84(0.80,0.88)$ & $0.83(0.77,0.90)$ & 0.870 \\
$\mathrm{MeHg}, \mu \mathrm{g} / \mathrm{L}$ & $0.74(0.71,0.76)$ & $0.74(0.71,0.78)$ & 0.922 & & $0.59(0.56,0.63)$ & $0.61(0.55,0.67)$ & 0.740 \\
$\mathrm{MeHg} / \mathrm{THg}$ & $0.75(0.74,0.75)$ & $0.75(0.74,0.76)$ & 0.495 & & $0.71(0.69,0.73)$ & $0.73(0.70,0.75)$ & 0.292 \\
\hline
\end{tabular}

Full: $\geq 15$ years old; Reproductive: women 15 to 44 years old. NHANES, National Health and Nutrition Examination Survey; $\mathrm{THg}$, total mercury; $\mathrm{MeHg}$, methylmercury. Values for $\mathrm{THg}$ and $\mathrm{MeHg}$ are geometric mean (95\% confidence interval); values for $\mathrm{MeHg} / \mathrm{THg}$ are mean (95\% confidence interval). $p$ values are a comparison of training versus test datasets using a Wald test test datasets, the geometric mean $(95 \% \mathrm{CI})$ was $0.99 \mu \mathrm{g} / \mathrm{L}$ $(0.97,1.01)$ for $\mathrm{THg}$ and $0.74 \mu \mathrm{g} / \mathrm{L}(0.72,0.76)$ for $\mathrm{MeHg}$; mean (95\% CI) MeHg/THg was 0.80 (0.79, 0.80). There were no statistically significant differences in these values in the training versus test datasets. The relationship between $\mathrm{MeHg}$ and $\mathrm{THg}$ was visually displayed using nonparametric lowess plots (Supplementary Information, Figure S2) and box plots of the MeHg/THg ratio by quartile of $\mathrm{THg}$ (Fig. 1). The $\mathrm{MeHg} / \mathrm{THg}$ ratio was significantly higher among those with higher $\mathrm{THg}$ concentrations: the average $\mathrm{MeHg} / \mathrm{THg}$ ratio was 0.65 for those in the lowest quintile of $\mathrm{THg}$ but was 0.94 for those in the highest quintile of $\mathrm{THg}$ (Fig. 1).

Average blood $\mathrm{Hg}$ concentrations and the $\mathrm{MeHg} / \mathrm{THg}$ ratio stratified by demographic characteristics are presented in Table 3. THg and MeHg blood concentrations were significantly higher among those of older age, men, non-Hispanic Asians, non-Hispanic blacks (full adult population only), participants with a higher household income, and participants with a lower BMI. The $\mathrm{MeHg} / \mathrm{THg}$ ratio was also higher among these groups.

Regression model results using the training dataset to predict blood $\mathrm{MeHg}$ are presented in Tables S1 and S2. In the unadjusted linear model among the full adult population, the $\beta$ coefficient for $\mathrm{THg}$ was 1.01 (95\% CI: $1.00,1.01)$. In unadjusted spline models among the full adult population, the $\beta$ coefficient for $\mathrm{THg}$ values $\leq 1 \mu \mathrm{g} / \mathrm{L}$ was 0.88 (95\% CI: $0.85,0.91$ ), and $\beta$ for $\mathrm{THg}>1 \mu \mathrm{g} / \mathrm{L}$ was 1.01 (95\% CI: 1.01 , 1.02). $\beta$ coefficients for THg were not substantially affected by the population or adjustment for additional covariates; all THg coefficients were statistically significant. In adjusted models, other coefficients which were statistically significant included age (women of reproductive age only), sex (full adult only), Hispanic (vs. non-Hispanic white, women of reproductive age only), Asian (vs. non-Hispanic white, full adult only) and non-Hispanic black (vs. non-Hispanic white, full adult only), income (women of reproductive age only), and obese (vs. normal weight, full adult only). An increase in blood $\mathrm{THg}$ at low concentrations $(\leq 1 \mu \mathrm{g} / \mathrm{L})$ was associated with a significantly smaller increase in estimated blood MeHg ( $\beta$ : 0.88, 95\% CI: $0.85,0.91)$ compared to an increase in $\mathrm{THg}$ at higher concentrations $(>1 \mu \mathrm{g} / \mathrm{L})(\beta: 1.01$, 95\% CI: $1.01,1.02$ ).

Indicators of model fit for the training dataset are shown in Table 4 and Figures S3 to S6 (Supplementary Information). These were very similar across the different models, and overall indicated a very good model fit. $R^{2}$ values for models among the full adult population, rounded to three decimal places, were 0.982 , and ranged from 0.957 to 0.959 for the women of reproductive age population. Median model residuals ranged from $0.02 \mu \mathrm{g} / \mathrm{L}$ (interquartile range (IQR): $-0.07,0.12$ ) in the unadjusted spline model for the women of reproductive age population to $0.04 \mu \mathrm{g} / \mathrm{L}$ (IQR: $-0.09,0.12$ ) in the unadjusted linear model for the full adult population.

The linear THg and spline THg models were then used to predict $\mathrm{MeHg}$ using the test dataset; model fit statistics are presented in Table 5 and Figures S7 to S10 (Supplementary Information). Overall, these also suggested excellent model fit. Median model residuals ranged from 0.02 (interquartile range (IQR): $-0.09,0.12$ ) in the spline models among the

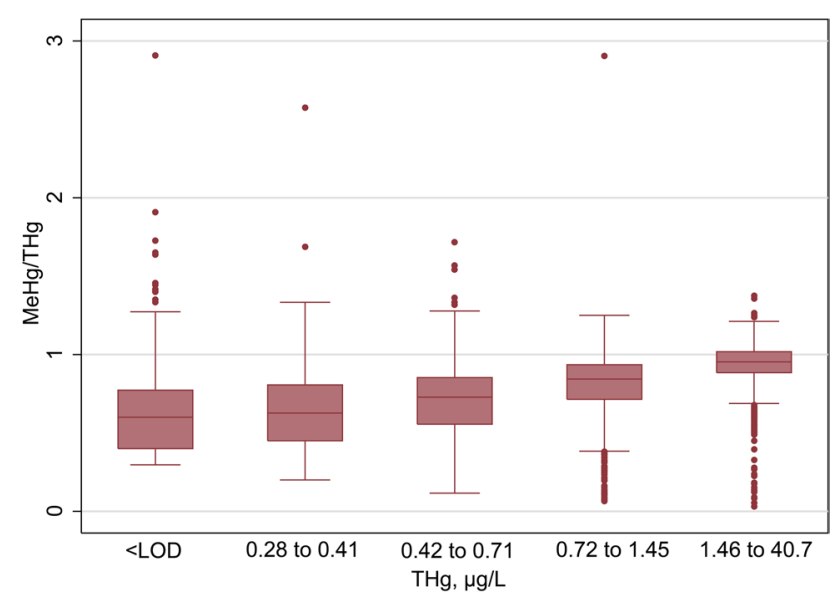

Fig. 1 Boxplots displaying the distribution of methylmercury/total mercury ( $y$-axis) by quintile of total mercury ( $x$-axis) among fish and shellfish consumers at least 15 years of age (full adult population) from the training dataset, $N=5268$ 
Table 3 Total and methylmercury concentrations by selected covariates, fish and shellfish consumers, NHANES 2011-2016

\begin{tabular}{|c|c|c|c|c|c|c|}
\hline \multirow[t]{2}{*}{ Variable } & \multicolumn{3}{|c|}{ Full adult population $(n=7604)$} & \multicolumn{3}{|c|}{ Women of reproductive age $(n=1845)$} \\
\hline & $\mathrm{THg}$ & $\mathrm{MeHg}$ & $\mathrm{MeHg} / \mathrm{THg}$ & $\mathrm{THg}$ & $\mathrm{MeHg}$ & $\mathrm{MeHg} / \mathrm{THg}$ \\
\hline \multicolumn{7}{|l|}{ Age } \\
\hline $15-29^{a}$ & $0.76(0.73,0.79)$ & $0.56(0.53,0.59)$ & $0.79(0.78,0.81)$ & $0.75(0.71,0.80)$ & $0.54(0.50,0.58)$ & $0.78(0.76,0.80)$ \\
\hline $30-44$ & $0.98(0.94,1.03)$ & $0.73(0.69,0.77)$ & $0.79(0.78,0.80)$ & $0.93(0.88,0.99)$ & $0.66(0.61,0.71)$ & $0.76(0.75,0.78)$ \\
\hline $45-59$ & $1.21(1.15,1.26)$ & $0.92(0.86,0.97)$ & $0.81(0.80,0.82)$ & - & - & - \\
\hline $60+$ & $1.06(1.02,1.10)$ & $0.79(0.75,0.83)$ & $0.80(0.79,0.81)$ & - & - & - \\
\hline \multicolumn{7}{|l|}{ Sex } \\
\hline Female $^{\mathrm{a}}$ & $0.96(0.93,0.99)$ & $0.69(0.67,0.72)$ & $0.78(0.77,0.79)$ & - & - & - \\
\hline Male & $1.02(0.99,1.06)$ & $0.79(0.76,0.82)$ & $0.82(0.81,0.82)$ & - & - & - \\
\hline \multicolumn{7}{|l|}{ Race/ethnicity } \\
\hline NH white ${ }^{a}$ & $0.86(0.83,0.89)$ & $0.61(0.58,0.64)$ & $0.77(0.76,0.78)$ & $0.73(0.67,0.78)$ & $0.51(0.46,0.56)$ & $0.76(0.74,0.78)$ \\
\hline NH black & $0.92(0.88,0.95)$ & $0.72(0.69,0.75)$ & $0.82(0.81,0.83)$ & $0.75(0.69,0.81)$ & $0.54(0.49,0.59)$ & $0.77(0.75,0.79)$ \\
\hline Hispanic & $0.82(0.79,0.86)$ & $0.57(0.55,0.60)$ & $0.75(0.74,0.77)$ & $0.69(0.65,0.74)$ & $0.45(0.42,0.50)$ & $0.72(0.70,0.74)$ \\
\hline NH Asian & $2.61(2.46,2.78)$ & $2.36(2.20,2.54)$ & $0.93(0.92,0.94)$ & $2.01(1.79,2.25)$ & $1.73(1.51,1.99)$ & $0.90(0.87,0.92)$ \\
\hline Multiracial/other & $0.92(0.81,1.04)$ & $0.68(0.58,0.79)$ & $0.79(0.76,0.81)$ & $0.80(0.64,1.02)$ & $0.56(0.41,0.75)$ & $0.75(0.69,0.80)$ \\
\hline \multicolumn{7}{|l|}{ Household income } \\
\hline$<\$ 20,000^{\mathrm{a}}$ & $0.81(0.77,0.84)$ & $0.57(0.54,0.61)$ & $0.77(0.76,0.79)$ & $0.71(0.65,0.77)$ & $0.48(0.43,0.54)$ & $0.75(0.72,0.78)$ \\
\hline$\$ 20,000$ to $\$ 44,999$ & $0.83(0.80,0.86)$ & $0.60(0.57,0.63)$ & $0.77(0.76,0.78)$ & $0.70(0.65,0.74)$ & $0.47(0.43,0.52)$ & $0.74(0.72,0.76)$ \\
\hline$\$ 45,000$ to $\$ 74,999$ & $1.00(0.95,1.05)$ & $0.74(0.69,0.78)$ & $0.79(0.78,0.80)$ & $0.81(0.74,0.88)$ & $0.57(0.50,0.64)$ & $0.76(0.74,0.79)$ \\
\hline$\geq \$ 75,000$ & $1.34(1.29,1.40)$ & $1.08(1.03,1.13)$ & $0.84(0.83,0.85)$ & $1.16(1.06,1.26)$ & $0.90(0.82,1.00)$ & $0.83(0.81,0.85)$ \\
\hline \multicolumn{7}{|l|}{ BMI } \\
\hline Under/normal weight ${ }^{a}$ & $1.12(1.07,1.16)$ & $0.86(0.82,0.91)$ & $0.82(0.81,0.83)$ & $0.97(0.90,1.04)$ & $0.72(0.65,0.78)$ & $0.80(0.78,0.81)$ \\
\hline Overweight & $1.03(0.99,1.07)$ & $0.77(0.73,0.81)$ & $0.80(0.79,0.81)$ & $0.84(0.77,0.91)$ & $0.61(0.55,0.67)$ & $0.78(0.76,0.80)$ \\
\hline Obese & $0.86(0.84,0.89)$ & $0.62(0.59,0.64)$ & $0.77(0.76,0.78)$ & $0.70(0.66,0.75)$ & $0.48(0.44,0.52)$ & $0.74(0.72,0.76)$ \\
\hline
\end{tabular}

Full: $\geq 15$ years old; Reproductive: women 15 to 44 years old. Data include both training and test datasets. Statistical tests were Wald tests to determine whether there was a significant difference in mercury concentration compared to the referent group. Bold type: Wald test $p<0.05$. Italic type: $p<0.10 .{ }^{\mathrm{a}}$ Referent

Table 4 Model performance indicators, fish and shellfish consumers, training dataset

\begin{tabular}{|c|c|c|c|c|c|c|c|}
\hline Model & Adj. $R^{2}$ & Root MSE & AIC & $\mathrm{BIC}$ & Predicted $\mathrm{MeHg}^{\text {a }}$ & Residual $^{\mathrm{a}}$ & Leverage $\times 1000^{\mathrm{a}}$ \\
\hline \multicolumn{8}{|c|}{ Full adult population ${ }^{\mathrm{b}}$} \\
\hline \multicolumn{8}{|l|}{ Linear } \\
\hline Unadjusted & 0.982 & 0.318 & 2883 & 2896 & $0.74(0.34,1.70)$ & $0.04(-0.09,0.12)$ & $0.23(0.20,0.25)$ \\
\hline Adjusted & 0.982 & 0.316 & 2837 & 2922 & $0.74(0.33,1.70)$ & $0.03(-0.08,0.12)$ & $2.15(1.902 .47)$ \\
\hline \multicolumn{8}{|l|}{ Spline } \\
\hline Unadjusted & 0.982 & 0.316 & 2826 & 2845 & $0.71(0.36,1.67)$ & $0.02(-0.09,0.12)$ & $0.38(0.33,0.48)$ \\
\hline Adjusted & 0.982 & 0.314 & 2768 & 2860 & $0.71(0.35,1.67)$ & $0.02(-0.09,0.11)$ & $2.33(2.06,2.70)$ \\
\hline \multicolumn{8}{|c|}{ Women of reproductive age ${ }^{c}$} \\
\hline \multicolumn{8}{|l|}{ Linear } \\
\hline Unadjusted & 0.957 & 0.347 & 928 & 938 & $0.60(0.29,1.34)$ & $0.03(-0.07,0.11)$ & $0.97(0.85,1.09)$ \\
\hline Adjusted & 0.959 & 0.342 & 904 & 965 & $0.60(0.27,1.32)$ & $0.03(-0.08,0.12)$ & $8.15(7.16,9.54)$ \\
\hline \multicolumn{8}{|l|}{ Spline } \\
\hline Unadjusted & 0.958 & 0.346 & 922 & 938 & $0.59(0.31,1.31)$ & $0.02(-0.07,0.12)$ & $1.72(1.27,2.16)$ \\
\hline Adjusted & 0.959 & 0.341 & 897 & 964 & $0.59(0.29,1.30)$ & $0.02(-0.08,0.12)$ & $8.98(7.87,10.36)$ \\
\hline
\end{tabular}

$\mathrm{MeHg}$, methylmercury; $\mathrm{MSE}$, mean squared error; AIC, Akaike's information criterion; BIC, Bayesian Information Criterion

${ }^{a}$ Median (interquartile range) in $\mu \mathrm{g} / \mathrm{L}$

${ }^{b}$ Full: $\geq 15$ years old, $N=5268$. Median (interquartile range) for measured $\mathrm{MeHg}$ is $0.71(0.32,1.68)$

${ }^{\mathrm{c}}$ Reproductive: women 15 to 44 years old, $N=1285$. Median (interquartile range) for measured $\mathrm{MeHg}$ is $0.55(0.27,1.32)$ 
Table 5 Model performance indicators, fish and shellfish consumers, test dataset

\begin{tabular}{lcclc}
\hline Population and model & Measured MeHg & Predicted MeHg $^{\mathrm{a}}$ & Residual $^{\mathrm{a}}$ & ${\text { Leverage } \times 1000^{\mathrm{a}}}^{\mathrm{a}}$ \\
\hline $\begin{array}{l}\text { Full adult population }(n=2336) \\
\text { Linear }\end{array}$ & & & \\
$\quad$ Unadjusted & $0.70(0.33,1.61)$ & $0.72(0.34,1.63)$ & $0.03(-0.09,0.12)$ & $0.23(0.20,0.25)$ \\
$\quad$ Adjusted & $0.70(0.33,1.61)$ & $0.72(0.33,1.64)$ & $0.03(-0.09,0.12)$ & $2.13(1.90,2.45)$ \\
Spline & & & & \\
$\quad$ Unadjusted & $0.70(0.33,1.61)$ & $0.69(0.36,1.60)$ & $0.02(-0.09,0.12)$ & $0.39(0.33,0.47)$ \\
$\quad$ Adjusted & $0.70(0.33,1.61)$ & $0.70(0.36,1.61)$ & $0.02(-0.09,0.12)$ & $2.33(2.05,2.69)$ \\
Women of reproductive age $(N=560)$ & & & \\
Linear & & & & \\
$\quad$ Unadjusted & $0.58(0.27,1.29)$ & $0.56(0.27,1.31)$ & $0.03(-0.07,0.11)$ & $0.96(0.85,1.09)$ \\
$\quad$ Adjusted & $0.58(0.27,1.29)$ & $0.59(0.26,1.29)$ & $0.02(-0.07,0.13)$ & $8.15(7.16,9.51)$ \\
Spline & & & & $1.69(1.27,2.15)$ \\
$\quad$ Unadjusted & $0.58(0.27,1.29)$ & $0.55(0.29,1.28)$ & $0.03(-0.07,0.12)$ & \\
$\quad$ Adjusted & $0.58(0.27,1.29)$ & $0.57(0.29,1.26)$ & $0.02(-0.07,0.12)$ & $8.87(7.84,10.34)$
\end{tabular}

Full: $\geq 15$ years old; Reproductive: women 15 to 44 years old. ${ }^{a}$ Median (interquartile range) in $\mu \mathrm{g} / \mathrm{L}$ full adult population to 0.03 (IQR: $-0.09,0.12$ ) in the linear model among the full adult population.

Estimated $\mathrm{MeHg}$ for selected values for $\mathrm{THg}$ using this unadjusted spline model are presented in Table S3 (Supplementary Information). For a $\mathrm{THg}$ blood concentration of $3.40 \mu \mathrm{g} / \mathrm{L}$, the predicted blood $\mathrm{MeHg}$ concentration would be $3.22 \mu \mathrm{g} / \mathrm{L}$ among the full adult population and $3.18 \mu \mathrm{g} / \mathrm{L}$ among women of reproductive age. Corresponding values for a blood $\mathrm{THg}$ concentration of $5.80 \mu \mathrm{g} / \mathrm{L}$ are blood $\mathrm{MeHg}$ concentrations of $5.65 \mu \mathrm{g} / \mathrm{L}$ and $5.55 \mu \mathrm{g} / \mathrm{L}$, respectively, for the full adult population and the women of reproductive age population.

\section{Discussion}

This analysis used a representative sample of the adult population of fish and shellfish consumers and a subset of women of reproductive ages from the USA to develop and test a model which would predict blood $\mathrm{MeHg}$ concentrations using blood $\mathrm{THg}$ concentrations. After testing several models, we selected the unadjusted spline model for prediction of $\mathrm{MeHg}$ : its performance is excellent, and due to its relative simplicity, it can be applied even when a limited amount of data from the original study is available.

Although we are not aware of other models that estimate blood $\mathrm{MeHg}$ based on blood $\mathrm{THg}$, several investigators have reported on a key parameter influencing this model: the $\mathrm{MeHg} / \mathrm{THg}$ ratio. This analysis of the training dataset found that the average blood $\mathrm{MeHg} / \mathrm{THg}$ ratio was 0.75 (Table 2). This is similar to reported values: 0.69 to 0.85 from other analyses of NHANES data [28, 30]; 0.63 from pregnant women in North Carolina [23]; 0.52 to 0.88 from populations in Europe [24, 31-34]; 0.86 from pregnant women in Suriname [35]; 0.72 to 0.93 from populations in Asia [22, 29, 36]; and 0.91 among newcomers to Canada [37]. Although the exact reason for the variation across populations is not known, it is possible this is related to differences in demographics or diet. Across both datasets, significant associations were observed between the $\mathrm{MeHg} / \mathrm{THg}$ ratio and sex, race/ethnicity, income, BMI, and fish and shellfish consumption (Table 3).

In this analysis, the $\mathrm{MeHg} / \mathrm{THg}$ ratio was higher among those with higher $\mathrm{THg}$ concentrations. This positive correlation of the $\mathrm{MeHg} / \mathrm{THg}$ ratio with $\mathrm{THg}$ concentration has also been observed in several prior studies [23, 24, 29, 38]. Interestingly, two studies have also reported negative correlations $[22,23]$. However, these might be explained by differences in study design (measurement in late pregnancy) [23] or population (substantially higher THg concentrations) [22]. Among those with lower THg exposure, there may be a higher proportion of elemental or inorganic $\mathrm{Hg}$ from sources such as dental amalgams or some foods [24, 39].

This analysis has a few limitations. First, the detection limit for THg in several NHANES cycles was high $(0.28 \mu \mathrm{g} / \mathrm{L})$. Due to this, some groups with lower $\mathrm{THg}$ exposure (children and those who do not consume fish or shellfish) were not included in this analysis. Additionally, estimates for blood $\mathrm{MeHg}$ for those with lower $\mathrm{THg}$ concentrations within our model may not be as precise as the estimates for those with higher THg exposure. Second, as we did not use survey weights in our analysis, our results cannot be assumed to reflect a representative sample of the US population. However, as the dataset was large, we feel that results are still robust.

There are also several strengths of this analysis. These results are likely to be of great use to risk assessors who need to synthesize data from studies on health risks related 
to blood $\mathrm{THg}$ instead of blood $\mathrm{MeHg}$. They are also consistent with the prior literature which compared blood THg to blood $\mathrm{MeHg}$ concentrations. Additionally, we present results specific to women of reproductive age, the demographic group commonly included in studies of the health effects of $\mathrm{MeHg}$ exposure.

\section{Conclusions}

This manuscript describes the development of the first model, of which we are aware, that predicts whole blood $\mathrm{MeHg}$ based on whole blood THg. For studies evaluating $\mathrm{MeHg}$ toxicity that rely only on blood $\mathrm{THg}$, this model can be used to convert blood $\mathrm{THg}$ concentrations to blood $\mathrm{MeHg}$ concentrations, and, therefore, to provide accurate estimates of exposure to $\mathrm{MeHg}$.

Supplementary Information The online version contains supplementary material available at https://doi.org/10.1007/s12011-021-02968-9.

Acknowledgements The authors wish to thank Glenn Rice and Krista Christensen for their review of this manuscript.

Author Contribution EMW acquired and analyzed the data as well as drafted the original manuscript. All authors substantially contributed to the conception, design, interpretation, and critical revisions of this manuscript. All authors have approved the submitted version of this manuscript and have agreed both to be personally accountable for the author's own contributions and to ensure that questions related to the accuracy or integrity of any part of the work, even ones in which the author was not personally involved, are appropriately investigated and resolved, and the resolution documented in the literature.

Funding EMW was supported under a faculty research participation program between the Oak Ridge Institute for Science and Education (ORISE) and the US EPA Center for Public Health and Environmental Assessment. The other authors were supported by the US EPA's Center for Public Health and Environmental Assessment.

Data availability National Health and Nutrition Examination Survey (NHANES) data are available from the US Centers for Disease Control and Prevention at https://www.cdc.gov/nchs/nhanes/. Stata code and additional quality assurance details used in this analysis are available from the US EPA's ScienceHub website at 10.23719/1520665.

Code Availability Upon publication of the manuscript, the code will be available at https://catalog.data.gov/dataset/epa-sciencehub.

The views expressed in this article are those of the authors and do not necessarily reflect the views or policies of the US Environmental Protection Agency (EPA).

\section{Declarations}

Ethics Approval and Consent to Participate NHANES participants sign informed consent agreements prior to participation; NHANES operates under an approved protocol from the NCHS Ethics Review Board.

Conflict of Interest The authors declare no competing interests.
Open Access This article is licensed under a Creative Commons Attribution 4.0 International License, which permits use, sharing, adaptation, distribution and reproduction in any medium or format, as long as you give appropriate credit to the original author(s) and the source, provide a link to the Creative Commons licence, and indicate if changes were made. The images or other third party material in this article are included in the article's Creative Commons licence, unless indicated otherwise in a credit line to the material. If material is not included in the article's Creative Commons licence and your intended use is not permitted by statutory regulation or exceeds the permitted use, you will need to obtain permission directly from the copyright holder. To view a copy of this licence, visit http://creativecommons.org/licenses/by/4.0/.

\section{References}

1. Barbone F, Rosolen V, Mariuz M et al (2019) Prenatal mercury exposure and child neurodevelopment outcomes at 18 months: results from the Mediterranean PHIME cohort. Int J Hyg Environ Health 222:9-21. https://doi.org/10.1016/j.ijheh.2018.07. 011

2. Debes F, Weihe P, Grandjean P (2016) Cognitive deficits at age 22 years associated with prenatal exposure to methylmercury. Cortex 74:358-369. https://doi.org/10.1016/j.cortex.2015.05. 017

3. Kim JH, Lee SJ, Kim SY et al (2016) Association of food consumption during pregnancy with mercury and lead levels in cord blood. Sci Total Environ 563-564:118-124. https://doi.org/10. 1016/j.scitotenv.2016.04.082

4. Carocci A, Rovito N, Sinicropi MS, Genchi G (2014) Mercury toxicity and neurodegenerative effects. Rev Environ Contam Toxicol 229:1-18. https://doi.org/10.1007/978-3-319-03777-6_1

5. Fields CA, Borak J, Louis ED (2017) Persistence of mercuryinduced motor and sensory neurotoxicity: systematic review of workers previously exposed to mercury vapor. Crit Rev Toxicol 47:845-866. https://doi.org/10.1080/10408444.2017.1342599

6. Murata K, Grandjean P, Dakeishi M (2007) Neurophysiological evidence of methylmercury neurotoxicity. Am J Ind Med 50:765-771. https://doi.org/10.1002/ajim.20471

7. Houston MC (2011) Role of mercury toxicity in hypertension, cardiovascular disease, and stroke. J Clin Hypertens (Greenwich) 13:621-627. https://doi.org/10.1111/j.1751-7176.2011.00489.x

8. Virtanen JK, Rissanen TH, Voutilainen S, Tuomainen T-P (2007) Mercury as a risk factor for cardiovascular diseases. J Nutr Biochem 18:75-85. https://doi.org/10.1016/j.jnutbio.2006.05.001

9. Bridges CC, Zalups RK (2017) The aging kidney and the nephrotoxic effects of mercury. J Toxicol Environ Health B Crit Rev 20:55-80. https://doi.org/10.1080/10937404.2016.1243501

10. Chan TYK (2011) Inorganic mercury poisoning associated with skin-lightening cosmetic products. Clin Toxicol (Phila) 49:886-891. https://doi.org/10.3109/15563650.2011.626425

11. WHO (2010) Ten chemicals of major public health concern. https://www.who.int/ipcs/assessment/public_health/chemicals_ phc/en/. Accessed 4 Jun 2019

12. Gibb H, O'Leary KG (2014) Mercury exposure and health impacts among individuals in the artisanal and small-scale gold mining community: a comprehensive review. Environ Health Perspect 122:667-672. https://doi.org/10.1289/ehp.1307864

13. Li P, Du B, Chan HM, Feng X (2015) Human inorganic mercury exposure, renal effects and possible pathways in Wanshan mercury mining area, China. Environ Res 140:198-204. https:// doi.org/10.1016/j.envres.2015.03.033

14. Mergler D, Anderson HA, Chan LHM et al (2007) Methylmercury exposure and health effects in humans: a worldwide concern. 
AMBIO: A Journal of the Human Environment 36:3-11. https:// doi.org/10.1579/0044-7447(2007)36[3:MEAHEI]2.0.CO;2

15. Sheehan MC, Burke TA, Navas-Acien A et al (2014) Global methylmercury exposure from seafood consumption and risk of developmental neurotoxicity: a systematic review. Bull World Health Organ 92:254-269F. https://doi.org/10.2471/BLT.12.116152

16. Berglund M, Lind B, Björnberg KA et al (2005) Inter-individual variations of human mercury exposure biomarkers: a cross-sectional assessment. Environ Health 4:20. https://doi.org/10.1186/ 1476-069X-4-20

17. Buchanan S, Anglen J, Turyk M (2015) Methyl mercury exposure in populations at risk: analysis of NHANES 2011-2012. Environ Res 140:56-64. https://doi.org/10.1016/j.envres.2015.03.005

18. Epa US (2001) Methylmercury chemical assessment summary. US Environmental Protection Agency, Washington, D.C.

19. US EPA O (2020) Methylmercury (MeHg). https://cfpub.epa.gov/ ncea/iris $2 /$ chemicalLanding.cfm?substance_nmbr=73. Accessed 4 Dec 2020

20. Stern AH, Smith AE (2003) An assessment of the cord blood:maternal blood methylmercury ratio: implications for risk assessment. Environ Health Perspect 111:1465-1470. https://doi. org/10.1289/ehp.6187

21. Grandjean P, Budtz-Jorgensen E, White RF et al (1999) Methylmercury exposure biomarkers as indicators of neurotoxicity in children aged 7 years. Am J Epidemiol 150:301-305

22. Jung SA, Chung D, On J et al (2013) Correlation between total mercury and methyl mercury-in whole blood of South Korean. Bull Korean Chem Soc 34:1101-1107. https://doi.org/10.5012/ bkcs.2013.34.4.1101

23. Donohue A, Wagner CL, Burch JB, Rothenberg SE (2018) Blood total mercury and methylmercury among pregnant mothers in Charleston, South Carolina, USA. J Expo Sci Environ Epidemiol 28:494-504. https://doi.org/10.1038/s41370-018-0033-1

24. Trdin A, Snoj Tratnik J, Mazej D et al (2019) Mercury speciation in prenatal exposure in Slovenian and Croatian population PHIME study. Environ Res 177:108627. https://doi.org/10.1016/j. envres.2019.108627

25. Wells EM, Herbstman JB, Lin YH et al (2017) Methyl mercury, but not inorganic mercury, associated with higher blood pressure during pregnancy. Environ Res 154:247-252. https://doi.org/10. 1016/j.envres.2017.01.013

26. CDC (2013) Laboratory Procedure Manual: Blood Metals Panel 2 (BMP2) ICP-DRC-MS. US Centers for Disease Control and Prevention, Atlanta, GA

27. CDC (2013) Laboratory Procedure Manual : Blood mercury speciation TSID-GC-ICP-DRC-MS. US Centers for Disease Control and Prevention, Atlanta, GA

28. Mortensen ME, Caudill SP, Caldwell KL et al (2014) Total and methyl mercury in whole blood measured for the first time in the U.S. population: NHANES 2011-2012. Environ Res 134:257264. https://doi.org/10.1016/j.envres.2014.07.019

29. You C-H, Kim B-G, Jo E-M et al (2012) The relationship between the fish consumption and blood total/methyl-mercury concentration of costal area in Korea. Neurotoxicology 33:676682. https://doi.org/10.1016/j.neuro.2012.04.005

30. Yin L, Yu K, Lin S et al (2016) Associations of blood mercury, inorganic mercury, methyl mercury and bisphenol A with dental surface restorations in the U.S. population, NHANES 2003-2004 and 2010-2012. Ecotoxicol Environ Saf 134:213-225. https://doi. org/10.1016/j.ecoenv.2016.09.001

31. Hansen JC, Tarp U, M.D JBDMO, (1990) Prenatal exposure to methyl mercury among Greenlandic Polar Inuits. Archives of Environmental Health: An International Journal 45:355-358. https://doi.org/10.1080/00039896.1990.10118754

32. Soria ML, Sanz P, Martínez D, et al. (1992) Total mercury and methylmercury in hair, maternal and umbilical blood, and placenta from women in the Seville area. Bulletin of Environmental Contamination and Toxicology 48. https://doi.org/10.1007/BF001 99063

33. Vahter M, Akesson A, Lind B et al (2000) Longitudinal study of methylmercury and inorganic mercury in blood and urine of pregnant and lactating women, as well as in umbilical cord blood. Environ Res 84:186-194. https://doi.org/10.1006/enrs.2000.4098

34. Ursinyova M, Masanova V, Uhnakova I et al (2019) Prenatal and early postnatal exposure to total mercury and methylmercury from low maternal fish consumption. Biol Trace Elem Res 191:16-26. https://doi.org/10.1007/s12011-018-1585-6

35. Wickliffe JK, Lichtveld MY, Zijlmans CW et al (2020) Exposure to total and methylmercury among pregnant women in Suriname: sources and public health implications. J Expo Sci Environ Epidemiol. https://doi.org/10.1038/s41370-020-0233-3

36. Sakamoto M, Kaneoka T, Murata K et al (2007) Correlations between mercury concentrations in umbilical cord tissue and other biomarkers of fetal exposure to methylmercury in the Japanese population. Environ Res 103:106-111. https://doi.org/10.1016/j. envres.2006.03.004

37. Wiseman CLS, Parnia A, Chakravartty D et al (2019) Total, methyl and inorganic mercury concentrations in blood and environmental exposure sources in newcomer women in Toronto, Canada. Environ Res 169:261-271. https://doi.org/10.1016/j. envres.2018.11.011

38. Mahaffey KR (2005) Mercury exposure: medical and public health issues. Trans Am Clin Climatol Assoc 116:127-154

39. Wells EM, Kopylev L, Nachman R et al (2020) Seafood, wine, rice, vegetables, and other food items associated with mercury biomarkers among seafood and non-seafood consumers: NHANES 2011-2012. J Expo Sci Environ Epidemiol 30:504514. https://doi.org/10.1038/s41370-020-0206-6

Publisher's Note Springer Nature remains neutral with regard to jurisdictional claims in published maps and institutional affiliations. 